\title{
Clinicoepidemiological Profile and Short term Outcome of Abdominal Tuberculosis in Western Region of Bangladesh
}

\author{
M SAHA $^{\mathrm{a}}$, SAHMM ISLAM ${ }^{\mathrm{b}}$, I PERVEEN $^{\mathrm{C}}, \mathrm{NAKTAR}^{\mathrm{d}}, \mathrm{KAHMED}^{\mathrm{e}}$, MAA HELY $^{\mathrm{f}}$, \\ M ZAKARIA ${ }^{\mathrm{g}}$, MM HOQUE ${ }^{\mathrm{h}}$
}

\begin{abstract}
Summary:
Introduction: Abdominal tuberculosis is not uncommon in daily medical practice. This study was done focusing variable presentations of abdominal tuberculosis
\end{abstract}

Material and methods: Data of consecutive patients diagnosed as abdominal tuberculosis were analyzed. Their epidemiological features, presentations, laboratory findings, and response to therapy were analysed.

Result: Total 69 cases (male 43, 62.3\%, and female 26, $37.7 \%$ ), age ranging from 15 to 85 years (mean 36.23) were enrolled. Rural (55, 79.7\%), poor (49,71\%) and housewives (24, 34.8\%) and people of $21-30$ years age group $(27,39.1 \%)$ were more affected. Diagnosis was based on combinations of clinical, laboratory findings and therapeutic response. In this series 30 (43.5\%), 23 (33.4\%) and 12 (17.3\%) were

\section{Introduction:}

Tuberculosis is a life threatening disease which can affect any organ system ${ }^{1}$. Abdominal tuberculosis (ATB) is defined as an infection in the gastrointestinal tract, peritoneum or intra-abdominal solid organs by Mycobacterium tuberculosis. It constitutes about 12\%

a. Prof. Madhusudan Saha, Professor, Department of Gastroenterology, North East Medical College, Sylhet

b. Dr. SAHM Mesbahul Islam, Associate Professor, Department of Respiratory Medicine, Sylhet MA G Osmani Medical College.

c. Prof. Irin Perveen, Professor, Department of Gastroenterology, Enam Medical College, Savar, Dhaka

d. Dr. Nasrin Aktar, Assistant Registrar, Department of Gastroenterology, North East Medical College, Sylhet

e. Dr. Kabir Ahmed, Medical Officer, Department of Gastroenterology, North East Medical College, Sylhet

f. Dr. Musammat Aklima Akter Hely, Medical Officer, Department of Gastroenterology, North East Medical College, Sylhet

g. Dr. Mohammad Zakaria, Medical Officer, Department of Gastroenterology, North East Medical College, Sylhet

h. Dr. Md. Mazharul Hoque, Medical Officer, Department of Gastroenterology, North East Medical College, Sylhet

Address of Correspondence: Madhusudan Saha, Department of Gastroenterology, North East Medical College, Sylhet, Tel:+8801711367847, Email: madhunibedita@gmail.com

Received: 06 May, 2018

Accepted: 06 November, 2018 diagnosed as intestinal, peritoneal and disseminated tuberculosis respectively. Of them 68 patients recovered with treatment. Five patients developed intestinal obstruction and one developed hepatitis and lost from follow up.

Conclusion: Diagnosis of abdominal tuberculosis is by combinations of clinical findings, without gold standard method. In our series intestinal tuberculosis and peritoneal tuberculosis were common clinical types with weight loss and abdominal pain as common clinical symptoms. And outcome of Treatment of TB was excellent

Key words: Abdominal tuberculosis, intestinal tuberculosis, peritoneal tuberculosis

(J Bangladesh Coll Phys Surg 2019; 37: 25-29)

DOI: http://dx.doi.org/10.3329/jbcps.v37i1.39288

of extra pulmonary tuberculosis and $1-3 \%$ of all cases of tuberculosis ${ }^{2,3}$. Abdominal tuberculosis although less common in western countries, constitutes a major public health problem in developing countries and associated with significant morbidity and mortality $4,5,6$. It can have varied presentations, frequently mimicking other common and rare diseases such as malignancy, bacterial infectious disease, and inflammatory diseases ${ }^{7,8}$. Approximately $15-25 \%$ of cases with abdominal tuberculosis have concomitant pulmonary tuberculosis ${ }^{9,10}$. The World Health Organization estimates that one third of world's population is infected with $M$. tuberculosis, with the highest prevalence of TB in South east Asia ${ }^{11}$. Abdominal tuberculosis is predominantly a disease of young adult. Two third of the patients are 21-40 year old with equal sex incidence ${ }^{12}$. Abdominal tuberculosis has a myriad of presentation. Presentation varies from asymptomatic state to surgical emergency. Abdominal pain, constipation and vomiting, recurrent attacks of sub-acute intestinal obstruction, localized or generalized ascites and abdominal distension, diarrhea, fever, weight loss, per rectal bleeding or melaena may be the presenting features ${ }^{13}$. Like other countries tuberculosis especially abdominal tuberculosis is also encountered in daily practice in our country, but 
epidemiological data is scanty. With this background this study was designed focusing clinical profile of patients of abdominal tuberculosis in North East Part of Bangladesh.

\section{Materials and method:}

This observational study was carried out from January 2012 to December 2016 in Sylhet. All patients diagnosed as abdominal tuberculosis in the department of Gastroenterology of North East Medical College Hospital, Sylhet, Bangladesh were included. Clinical informations, including age, sex, medical, personal history, symptoms, signs - physical findings, laboratory, reports, imaging findings, endoscopic or colonoscopic findings with histopathological reports, ascetic fluid analysis were retrieved. Depending on clinical and laboratory findings, diagnosis were made and treatment with anti-tubercular drugs were given with follow up.

\section{Statistical analysis:}

Statistical analysis was done using SPSS version 20. Descriptive analysis of the data was done by using frequency and percentage for categorical variables, and mean and standard deviation for quantitative variables.

\section{Result:}

Total 69 patients (male 43, 62.3\% and female 26, $37.7 \%$ ), age varying from 15 years to 85 years (mean 36.23 and SD 14.97) were enrolled. Among them 55 $(79.7 \%)$ were from rural area. Of them housewives $(24,34.3 \%)$ were affected more, followed by farmers $(10,14.5 \%)$ and students and business men $(9,13 \%)$. In this series $49(71 \%)$ were from poor economic group and 19 (27.7\%) were from middle class group. Among all 44 (63.8\%) and 24 (34.8\%) were smoker and betel nut chewer respectively. In this series 11 (15.9\%) had family history of tuberculosis.

Common symptoms were abdominal pain $(42,60.9 \%)$, weight loss $(48,69.6 \%)$, fever $(22,31.9 \%)$, ascites $(25,36.2 \%)$, diarrhea $(23.2 \%)$ and abdominal mass $(16,23.2 \%)$. In this series $30(43.5 \%)$ had intestinal tuberculosis, 23 (33.4\%) had peritoneal tuberculosis. Disseminated tuberculosis was found in $12(17.3 \%)$ cases. In addition one case of oesophageal $(1,1.4 \%)$, one case of duodenal $(1,1.4 \%)$, one case of splenic $(1,1.4 \%)$ and one case of pancreatic tuberculosis $(1$, $1.4 \%$ ) were found in this study. Fifteen patient had foci of pulmonary tuberculosis and two had pleural effusion

\section{Table-I}

Showing demographic and clinical findingds

Variables

Age group

\begin{tabular}{|c|c|c|c|}
\hline \multirow[t]{5}{*}{ Age group } & Up to 20 years & 8 & $11.6 \%$ \\
\hline & $21-30$ & 27 & 39.1 \\
\hline & $31-40$ & 11 & 15.9 \\
\hline & $41-50$ & 14 & 20.3 \\
\hline & 51 and above & 9 & 13 \\
\hline \multirow[t]{2}{*}{ Sex } & Male & 43 & 62.3 \\
\hline & Female & 26 & 37.7 \\
\hline \multirow[t]{2}{*}{ Residence } & Urban & 14 & 20.3 \\
\hline & Rural & 55 & 79.7 \\
\hline \multirow[t]{7}{*}{ Occupation } & student & 9 & 13 \\
\hline & service & 3 & 4.3 \\
\hline & Housewife & 24 & 34.8 \\
\hline & Business & 9 & 13 \\
\hline & Farmer & 10 & 14.5 \\
\hline & Self employed & 8 & 11.5 \\
\hline & Others & 6 & 8.6 \\
\hline \multirow{4}{*}{$\begin{array}{l}\text { Economic } \\
\text { group }\end{array}$} & Poor & 14 & 20.3 \\
\hline & Lower middle class & 35 & 50.7 \\
\hline & Middle class & 19 & 27.5 \\
\hline & Rich & 01 & 1.4 \\
\hline \multirow[t]{2}{*}{ Personal habit } & Tobacco chewer & 24 & 34.8 \\
\hline & Smoker & 25 & 36.2 \\
\hline \multirow{12}{*}{$\begin{array}{l}\text { Family history } \\
\text { of Symptoms }\end{array}$} & Tuberculosis & 11 & 15.9 \\
\hline & Diarrhoea & 16 & 23.2 \\
\hline & Mass in abdomen & 16 & 23.2 \\
\hline & Bleeding per rectum & 1 & 1.4 \\
\hline & Ascites & 25 & 36.2 \\
\hline & Intestinal obstruction & 5 & 7.2 \\
\hline & dysphagia & 1 & 1.4 \\
\hline & Constipation & 1 & 1.4 \\
\hline & Fever & 22 & 31.9 \\
\hline & Cough & 7 & 10.1 \\
\hline & Weight loss & 48 & 69.6 \\
\hline & Pain abdomen & 42 & 60.9 \\
\hline \multirow[t]{7}{*}{ Diagnosis } & Intestinal TB & 30 & 43.5 \\
\hline & Peritoneal TB & 24 & 34.8 \\
\hline & Oesophageal TB & 1 & 1.4 \\
\hline & Duodenal TB & 1 & 1.4 \\
\hline & Splenic TB & 1 & 1.4 \\
\hline & Pancreatic TB & 1 & 1.4 \\
\hline & Disseminated TB & 11 & 15.9 \\
\hline
\end{tabular}




\section{Table-II}

\begin{tabular}{|c|c|c|c|}
\hline \multicolumn{4}{|c|}{ Investigations } \\
\hline \multicolumn{2}{|l|}{ Variables } & Frequency & Percentage \\
\hline \multirow[t]{4}{*}{$\mathrm{X}-\mathrm{R}$ ay chest $\mathrm{P}-\mathrm{A}$ View $\mathrm{n}=47$} & Normal & 29 & \\
\hline & $\mathrm{TB}$ & 15 & \\
\hline & Hilar lymphadenopathy & 1 & \\
\hline & Pleural Effusion & 2 & \\
\hline \multirow[t]{5}{*}{ USG of abdomen $(\mathrm{N}=56)$} & Ascites & 31 & \\
\hline & Abdominal lymphadenoapathy & 2 & \\
\hline & Abdominal masss & 10 & \\
\hline & Splenic lesion & 1 & \\
\hline & Normal & 12 & \\
\hline \multirow[t]{5}{*}{ Colonoscopy $(\mathrm{n}=40)$} & Ileo-caecal lesion & 19 & \\
\hline & Ascending colonic lesion & 18 & \\
\hline & Transverse colonic lesion & 1 & \\
\hline & Ileal lesion & 1 & \\
\hline & Left colonic lesion & 1 & \\
\hline \multirow[t]{2}{*}{ Upper GI endoscopy $(n=2)$} & Oesophageal lesion & 1 & \\
\hline & Duodenal lesion & 1 & \\
\hline \multirow[t]{2}{*}{ CT guided FNAC $(n=2)$} & Splenic TB & 1 & \\
\hline & Pancreatic TB & 1 & \\
\hline Sputum for AFB & Positive & 2 & \\
\hline
\end{tabular}

Table-III

\begin{tabular}{lcc} 
& Findings of Patients with ascites & \\
Variables & Range & Mean \\
\hline Age & $15-85$ & 34.7 SD 17.62 \\
Albumin in ascetic fluid & $1.54-4.12 \mathrm{gm} / \mathrm{dl}$ & 2.47 SD .52 \\
SAG & $0.35-1.05$ & 0.82 SD0.227 \\
Ascitic fluid ADA & $30-165$ & 67.87 \\
\hline
\end{tabular}

Table-IV

\begin{tabular}{lcc} 
& Outcome & \\
Outcome treatment & \\
\hline Recovered - no complication & Frequency & percentage \\
Obstruction need surgery - recovered & 63 & 91.6 \\
Obstruction without surgery recovered & 03 & 04.2 \\
Hepatitis and lost from follow up & 02 & 02.8 \\
\hline
\end{tabular}

among 48 patients undergoing X-Ray chest examinations. Two patients had cervical lymphadenopathy. Two patients were sputum positive for AFB among those having pulmonary foci. ESR of patients varied from $06 \mathrm{~mm}$ to $153 \mathrm{~mm}$ of $\mathrm{Hg}$ in first hour (mean 51.41). In this series six patients with intestinal tuberculosis had ascites. Among intestinal tuberculosis, predominant sites of involvement were ileocaecal region(47.5\%) and ascending colon(45\%). Histopathology showed granulomatous lesion. Mantoux test was equal or more than $10 \mathrm{~mm}$ in eight patients out of $13(61.53 \%)$ cases having done. 
Of 25 cases having ascites, SAG level varied from 0.35 to 1.4 (mean 0.82 and SD 0.22), lymphocyte counts varied from $80 \%$ to $100 \%$ (total count 50 to 7500 per cubic mm, mean 1306.66) and ascitic fluid ADA level from 30- 165 (mean 67.87). Ascitic fluid culture for AFB was not done. But AFB saining of ascitis fluid were negative in all cases of ascites.Mantoux test was performed in 10 patients and found 10 or more in six $(60 \%)$ cases

All the cases of intestinal, oesophageal, duodenal, splenic and pancreatic tuberculosis cases had lesion histopathologically or cytopathologically consistent with tuberculosis. Peritoneal tuberculosis was diagnosed on basis of clinical features, findings of Mantoux test, ascitic fluid analytic results positive response to anti-TB therapy. Disseminated tuberculosis cases were diagnosed by various combinations of clinical ndlabaoratory findings.

Most affected age group in this series is $21-30$ year $(27,39.1 \%)$. In this series one patient developed hepatitis and lost from follow up, five patients developed intestinal obstruction and three of them required surgery. At the end of six months treatment 68 patients recovered.

\section{Discussion:}

Tuberculosis is a chronic granulomatous disease caused by Mycobacterium tuberculosis. Pulmonary tuberculosis is most common form and it primarily involves the lungs, but any part of body can be involved by the disease 12. Among extra pulmonary tuberculosis, abdominal tuberculosis is one of the common disease 14,15,16. Abdominal tuberculosis constitutes a major public health problem in developing countries and carries significant morbidity and mortality $15,17,18,19,20$.

In this study males were predominantly affected Which is consistent with other studies 12,20,21,22. But from literature review the reason for this gender difference is not known. Majority of patients in this series were between 21 - 40 year age group followed by 41-50 year group and it is consistent with report from India ${ }^{23}$. The disease affects people at peaks of their productive life and causes considerable financial losses to the individual and family.
Common symptoms were abdominal pain and weight loss. Other symptoms were fever, abdominal swelling etc. Abdominal pain is a common symptom in other studies also. ${ }^{20,23}$. Intestinal tuberculosis and peritoneal tuberculosis are commonest form in this series which is also consistent with other reports $20,21,24$. Among intestinal tuberculosis, predominant site of involvement were ileocaecal region and ascending colon which supports the data from other studies 5,21 .

In our study fifteen patient had foci of pulmonary tuberculosis and two had pleural effusion on chest XRay examinations. Two patients were sputum positive for AFB. We cannot comment how many patients had primary abdominal tuberculosis as chest X-ray and other relevant investigations were not done in all cases.

In this series most of the patients represented poor economic class. Overcrowding, poor hygienic practice and poor nutritional status may play a role. In this series rural people are more affected and this could not be explained.

\section{Limitations of the study:}

Due to lack of facility and financial constrain culture for AFB and PCR for $M$. tuberculosis could not be done. So majority of the abdominal TB cases were diagnosed on the basis of clinical data, histopathological findings and respose to anti TB drug trial. Disseminated tuberculosis was found in 12 cases (27. 3\%). Disseminated TB was higher (37.74\%) in another study from Bangladesh ${ }^{15}$. In this study CXR, endoscopy of upper GIT and lower GIT and USG examinations were not done in all patients. And it might be the cause of lower rate of disseminated tuberculosis. We cannot say how many patients had drug resistant TB as culture and GeneXpert tests were not done. But 68 patients recovered with anti TB drugs suggesting that none had drug resistant TB.

\section{Conclusion:}

Abdominal tuberculosis is and important clinical entity among extra-pulmonary tuberculosis. Diagnosis of abdominal tuberculosis is by combinations of clinical findings, without gold standard method. In our series intestinal tuberculosis and peritoneal tuberculosis were common clinical types with weight loss and abdominal pain as common clinical presentation. And outcome of Treatment of TB was excellent 


\section{References:}

1. Rosado E, Penha D, Paixao P, Costa A. M. D, Amadora PT. Abdominal Tuberculosis - Imaging Findings. Educational Exhibit; ECR 2013: C- 0549.

2. WS Chen, SY Leu, H Hsu, JK Lin, TC Lin. Trend of large bowel tuberculosis and the relation with pulmonary tuberculosis. Dis Colon Rectum. 1992; 35: 189-92.

3. TA Sheer, WJ Coyle. Gastrointestinal tuberculosis. CurrGastroenterol Rep. 2003; 5: 273-8.

4. Organization WH, Global tuberculosis control, 2012, 2011.

5. N Wadhwa, S Agarwal, K Mishra. Reappraisal of abdominal tuberculosis. J Indian Med Assoc.; 2004; 102: 31-2.

6. Miah AR, Sharma YR, Rahman MT, Raihan A, Roy PK, Hasan M. Clinicopathological profile of patients with abdominal tuberculosis. J Nepal Health Res Counc. 2011; 9: 169-75.

7. PedaVeerraju E. Abdominal tuberculosis. In: Satya Sri S, editor. Textbook of Pulmonary and Extrapulmonary Tuberculosis. 3rd ed. New Delhi: Interprint; 1998:250-2.

8. Jadvar H, Mindelzun RE, Olcott EW, Levitt DB. Still the great mimicker: abdominal tuberculosis. AJR Am J Roentgenol 1997; 169: 602 .

9. Horvath KD, Whelan RL. Intestinal tuberculosis: return of an old disease. Am J Gastroenterol. 1998; 93: 692-6.

10. Akhan O, Pringot J. Imaging of abdominal tuberculosis. EurRadiol. 2002; 12:312-23.

11. Dolin PJ, Raviglione MC, Kochi A. Global tuberculosis incidence and mortality during 1990-2000. Bull World Health Organ. 1994; 72:213-20

12. Kapoor VK. Abdominal tuberculosis. Postgrad Med J. 1998; 74: 459-67.

13. Yunaev M, Ling A, Abbas S, Suen M, Pleass H. Abdominal tuberculosis: an easily forgotten diagnosis. ANZ journal of Surgery 2011; 81 (7-8): 559-60.

14. Al Karawi MA, Mohamed AE, Yasawy MI, etal. Protean manifestation of gastrointestinal tuberculosis. J ClinGastroenterol. 1995; 20: 225-32.

15. Vij JC, Malhotra V, Choudhary V, etal. A clinicopathological study of abdominal tuberculosis. Indian Journal of Tuberculosis. 1992; 39:213-20.

16. Pimparkar BD. Abdominal tuberculosis. J Assoc Physicians India. 1977; 25: 801-11.
17. Lönnroth K, Raviglione M. Global epidemiology of tuberculosis: prospects for control. SeminRespirCrit Care Med. 2008; 29: 48191.

18. Makharia GK, Srivastava S, Das P, etal. Clinical, endoscopic, and histological differentiations between Crohn's disease and intestinal tuberculosis. Am J Gastroenterol. 2010; 105: 642-51.

19. Chow KM, Chow VC, Hung LC, etal. Tuberculous peritonitisassociated mortality is high among patients waiting for the results of mycobacterial cultures of ascitic fluid samples. Clin Infect Dis. 2002 15; 35: 409-13.

20. Butt T, Karamat KA, Ahmed RN, Mahmood A. Advances in diagnosis in tuberculosis. Pak J. Path.

21. Chalya PL, Mchembe MD, Mshana SE, Rambau PF, Jaka H, Mabula JB. Clinicopathological profile and surgical treatment of abdominal tuberculosis: a single centre experience in northwestern Tanzania. BMC Infect Dis. 2013; 13: 270.

22. Rajpoot MJ, MemonAS, Rani S, Memon AH. Clinicopathological profile and surgical management outcomes in patients suffering from intestinal tuberculosis. J LiaqautUni Med Health Sci. 2005; 4: $113-8$.

23. Skopin MS, Batyrov FA, KornilovaZKh. The prevalence of abdominal tuberculosis and the specific features of its detection. ProblTuberkBoleznLegk. 2007; 1: 22-6.

24. Rao TMV, TV MK, Rao BB. Clinical profile of abdominal tuberculosis presenting to a tertiary care teaching hospital - A prospective observational study. International Archives of Integrated Medicine 2016; 3 (7): 267.

25. Hoon JR, Dockerty MB, Pemberton Jde J. Ileocecal tuberculosis including a comparison of this disease with nonspecific regional enterocolitis and noncaseoustuberculatedenterocolitis. IntAbstr Surg. 1950; 91: 417-40.

26. Malik AM, Talpur KA, Soomro AG, Qureshi JN. Yield of diagnostic laparoscopy in abdominal tuberculosis: is it worth attempting?SurgLaparoscEndoscPercutan Tech. 2011;21(3):1913.

27. Mandal A, Das SK, Bairagya TD. Presenting Experience of Managing Abdominal Tuberculosis at a Tertiary Care Hospital in India. J Glob Infect Dis. 2011; 3(4): 344-347.

28. Wani MU, Parvez M, Kumar SH, Naikoo GM, Jan M, Wani HA. Study of Surgical Emergencies of Tubercular Abdomen in Developing Countries. Indian J Surg. 2015; 77(3): 182-185. 